\title{
Possible neurogenic factor in muscular dystrophy: its similarity to denervation atrophy ${ }^{1}$
}

\author{
DARAB K. DASTUR AND ZOHRA A. RAZZAK
}

From the Neuropathology Unit, Postgraduate Research Laboratories, Grant Medical College and J.J. Group of Hospitals, Bombay-8, India

SUMMARY Muscle biopsy specimens from 179 cases of muscular dystrophies and from 140 cases of anterior horn cell disorders (from a total of 1,348 biopsied patients) were examined histologically. There were 72 cases of Duchenne type muscular dystrophy (DMD), five of Becker type MD, four girls with myopathy resembling DMD, 40 with limb-girdle, 10 with facioscapulohumeral, seven with late onset, 13 with congenital, and 28 with unclassifiable muscular dystrophies. Groups of small atrophied muscle fibres were encountered in $42(23 \%)$ of the cases in this group, most frequently in patients with limb-girdle, facioscapulohumeral, and least frequently with DM dystrophy. In the second group there were 25 cases of infantile, 38 of juvenile, and 39 of adult spinal muscular atrophy (SMA); there were 21 patients with motor neurone disease (MND), six with poliomyelitis, and 11 with an unclassifiable type of anterior horn cell disorder. Pseudomyopathic changes were encountered in $43(30 \%)$ of all cases in this group. They were most frequently present among patients with juvenile and adult SMA and in those with MND. The presence of group atrophy in muscular dystrophy is considered significant myopathological evidence of a denervation process. On the other hand, pseudomyopathic changes, variation in fibre size, rounding, central nuclei, and increase in connective tissue occurring in various anterior horn cell disorders are seen not to be specific 'myopathic' changes. Thus there was an overlap of pathological reactions in muscles from the dystrophies and the neurogenic atrophies. Comparably atrophied fibres (much less than 2 SDs below the normal mean diameter) and hypertrophied fibres (much more than 2 SDs above the normal mean diameter) were encountered in both dystrophy and neurogenic atrophy, considering the large muscles of the limb. Likewise, the mean fibre diameters were comparable in DMD and in juvenile SMA. The fourth evidence of a neurogenic factor in muscular dystrophy was derived from an examination of SDH preparations of muscle. There was a preponderance of type I muscle fibres in dystrophic muscles compared with specimens from controls, suggesting depletion of type II fibres. It appears that the concept of muscular dystrophy as a primary muscle disease needs to be re-examined.

While progressive muscular dystrophy of any type or variety has generally been held to be a primary muscle disorder, there have been some recent pointers to a possible neurogenic factor in muscular dystrophies, especially in the case of Duchenne type muscular dystrophy (DMD). Rosman and Kakulas (1966) observed abnormalities in the brain, including microscopic heterotopia of neurones in the cerebral white matter, in all their cases of muscular dystrophy

1 A part of this material was presented at the 2nd International Congress on Muscle Diseases at Perth, Australia, 22-26 November 1971. with clinical evidence of mental retardation. They ascribed the changes to a disorder of cortical development during foetal life. Zellweger and Niedermeyer (1965), among others, reported abnormality in the electroencephalogram (EEG) in a significant proportion of dystrophic children, in the form of 14 and 6/sec positive spikes, but without correlation with intellectual impairment. Zellweger and Hanson (1967) reported mental retardation in a third of their cases of DMD, even those in the early phases of the disease, and concluded that mental retardation is an intrinsic manifestation of the mutant gene. Cohen, Mol- 
nar, and Taft (1968) have also stressed the genetic relationship of the muscle pathology to the mental retardation in DMD. Dubowitz (1969) was impressed by the role of the nervous system in the development of muscular dystrophy. He summarized evidence showing that both the contractile and enzymic properties of the muscle fibres are controlled by the type of innervation of the muscle, and described apparent 'myopathic' features in muscle undergoing reinnervation.

McComas and Mrozek (1967) first provided electrophysiological evidence of denervated muscle fibres in hereditary muscular dystrophy of the mouse. More recently McComas, Sica, and Currie (1970) have presented 'perhaps the strongest evidence to date for a major, and possibly primary abnormality of the nerve supply to dystrophic muscle'. They observed a highly significant reduction in the number of motor units in the extensor digitorum brevis muscle of boys with DMD compared with normal boys of similar age. Because the amplitude of the motor unit action potentials remained normal in the presence of a clear fall in the number of electrical units, a selective denervation process destroying individual motor units in their entirety was suggested. McComas et al. (1970) also quoted unpublished observations of Tomlinson who 'has found a marked reduction in the number of motoneurones in the spinal cords of three cases of Duchenne dystrophy'. McComas, Sica, and Campbell (1971) have now hypothesized that there are a number of healthy, sick, and dead motoneurones in all types of muscular dystrophy, and the situation is comparable with that in various types of anterior horn cell disorder, only the tempo of degeneration of the motor nerve cell differing and thereby determining the pattern of muscle change.

At the same time, there has also been a growing body of information on pseudomyopathic changes in various forms of neurogenic atrophy. Drachman, Murphy, Nigam, and Hills (1967) demonstrated typical 'myopathic' changes, in addition to group atrophy, in biopsies of muscle from patients with old poliomyelitis. They rightly argued that in very long-standing cases with pure partial denervation such myopathic features may dominate the biopsy picture and lead to incorrect diagnosis. Kondo (1969) observed 'pseudo-dystrophic' features in muscle specimens from all of 14 cases of KugelbergWelander type of muscular atrophy.

We undertook a careful reappraisal of the histological changes in all the muscle biopsy specimens received till now at this Unit with a view to detecting changes of denervation, mainly group atrophy, in muscle dystrophies, and pseudomyopathic changes in neurogenic muscular atrophies resulting from anterior horn cell disorder. It was also decided to measure and compare the fibre diameters in a proportion of cases of typical muscular dystrophy and typical spinal muscular atrophy and to look for preponderance of one type of muscle fibre over another in suitable histochemical preparations.

\section{METHODS}

The case records of the patients from different hospitals, mainly from the J.J. Group of Hospitals and the Orthopaedic Hospital, were perused. The history was particularly utilized to derive the age of onset and the duration of the disease in each patient, and from this the averages for the type of disorder were calculated. Most of the patients of the last $4 \frac{1}{2}$ years of the period studied were examined and their histories obtained by us personally.

Muscle biopsy specimens (generally one specimen but often two) from 1,348 cases referred to this Unit $\bar{c}$ for myopathologic diagnosis over an 18 year period terminating with May 1971 constituted the material. A careful histological reappraisal of this material, as also of the clinical history in most of the cases, has finally revealed 179 biopsy-proven cases of muscular dystrophy of various types. Similarly, there were 140 biopsy-proven cases of various types of anterior horn cell disorder. Specimens with vague myopathic changes on the one hand, and with diffuse non-specific atrophy on the other, were not included in these groups.

All the biopsy specimens were fixed in formalin, blocked in paraffin, and sections stained with haematoxylin and eosin ( $\mathrm{H}$ and $\mathrm{E})$. Frequently PicroMallory (PM) stain for connective tissues and staining with phosphotungstic acid haematoxylin (PTAH) were carried out. In a number of cases fresh frozen sections were obtained and treated for detecting activity of oxidative enzymes and phosphorylase. Staining for succinic dehydrogenase (SDH) by the method of George and Talasera (1961) and for phosphorylase by the method of Takeuchi (1958) were employed; occasionally reduced nicotinamide adenine_dinucleotide $\left(\mathrm{NADH}_{2}\right)$ activity was also 
TABLE 1

GROUP ATROPHY IN VARIOUS TYPES OF MUSCULAR DYSTROPHY

\begin{tabular}{|c|c|c|c|c|c|c|c|c|c|}
\hline & $D M D$ & $\begin{array}{l}\text { Dystrophy of Du- } \\
\text { chenne type in girls }\end{array}$ & Becker type & Limb-girdle & $\begin{array}{c}\text { Facioscapulo- } \\
\text { humeral }\end{array}$ & Late onset & Congenital & Unclassifiable & Total \\
\hline No. of cases & 72 & 4 & 5 & 40 & 10 & 7 & 13 & 28 & 179 \\
\hline Group atrophy & 11 & - & - & 13 & 4 & - & 4 & 10 & 42 \\
\hline Male & 72 & 一 & 5 & 32 & 8 & 4 & 8 & $17^{*}$ & 146 \\
\hline Female & - & 4 & - & 8 & 2 & 3 & 5 & $2^{*}$ & 24 \\
\hline
\end{tabular}

* Sex not known in nine patients of this group.

looked for by the method of Engel and Brooke (1966).

Fibre diameters were measured in a proportion of the specimens in $\mathrm{H}$ and $\mathrm{E}$ stained paraffin sections and, where available, in frozen sections stained with SDH. Stage-cum-eyepiece micrometry was used. Atrophic muscle fibres when present in groups, in cases of both muscular dystrophy and denervation atrophy, were measured separately and compared with the diameters of the other fibres in the same section. In SDH stained frozen sections of specimens from muscular dystrophy, the ratio of type $I$ to type II fibres was compared.

Serum creatine phosphokinase (CPK) was estimated by the method of Hughes (1962) in almost all dystrophic patients and in many of those with denervation, during the last four years of the period under report. Electromyographic evaluation was available in the majority of patients during the last six years.

\section{OBSERVATIONS}

On the combined evidence of histopathological and clinical observations and the electrodiagnostic and serum CPK findings, where available, the type of muscle disorder in general, and of dystrophy or of anterior horn cell disorder in particular, were diagnosed. From the total of 1,348 cases, 179 or $13.3 \%$ were patients with muscular dystrophies, and 140 or $10.4 \%$ had anterior horn cell disorders.

MUSCULAR DYSTROPHIES (MD) The classification and incidence of the various types of dystrophies is given in Tables 1 and 2. Twenty-eight patients mentioned in Table 1 as 'unclassifiable' were cases of the early 1950s on whom no case records could be obtained. However, they appear to be a 'mixed bag' of dystrophies. The largest group consisted of patients with DMD with a mean age of 9.0 years (Tables 1 and 2). The four girls with a very similar disease and in a corresponding age group showed a comparable age of onset, while the five young men with the Becker-type of X-linked recessive dystrophy showed a clearly higher age of onset and a longer duration of illness indicating a benign course (Table 2). The expected higher age of onset is also seen for the limb-girdle and the facioscapulohumeral types of dystrophy, the former having a shorter and the latter a relatively longer duration. This is also reflected by the fact that, while the average age of onset of both these types of dystrophy was

TABLE 2

AGE AT EXAMINATION, DURATION, AND AGE OF ONSET IN DIFFERENT TYPES OF MUSCULAR DYSTROPHY

\begin{tabular}{|c|c|c|c|c|c|}
\hline \multirow{2}{*}{$\begin{array}{c}\text { Type of } \\
\text { dystrophy }\end{array}$} & \multicolumn{2}{|c|}{ Age (yr) } & \multicolumn{2}{|c|}{ Duration (yr) } & \multirow{2}{*}{$\begin{array}{c}\text { Average } \\
\text { age of } \\
\text { onset }(y r)\end{array}$} \\
\hline & Mean & Range & Average & Range & \\
\hline Duchenne & $9 \cdot 0$ & $3 \cdot 5-21$ & $4 \cdot 3$ & $0 \cdot 5-16$ & $4 \cdot 3$ \\
\hline $\begin{array}{l}\text { DMD-like in } \\
\text { girls }\end{array}$ & $9 \cdot 2$ & 6-13 & $4 \cdot 5$ & 4-5 & $4 \cdot 7$ \\
\hline Becker type & $26 \cdot 4$ & $19-44$ & $8 \cdot 8$ & $2-30$ & $17 \cdot 6$ \\
\hline Limb-girdle & $16 \cdot 8$ & $7-35$ & $3 \cdot 4$ & $0 \cdot 1-19$ & $13 \cdot 1$ \\
\hline $\begin{array}{l}\text { Facioscapulo- } \\
\text { humeral }\end{array}$ & $21 \cdot 1$ & $9-53$ & $7 \cdot 3$ & $0 \cdot 1-35$ & $12 \cdot 6$ \\
\hline Late onset & $33 \cdot 7$ & $25-45$ & $6 \cdot 1$ & $1-25$ & $26 \cdot 6$ \\
\hline Congenital & $5 \cdot 1$ & $1-13$ & $5 \cdot 1$ & $0-13$ & 0.0 \\
\hline
\end{tabular}

$\mathrm{DMD}=$ Duchenne muscular dystrophy. $0=$ From birth.

early in the second decade, more patients with the facioscapulohumeral type presented for examination at relatively older ages (up to 53 years). Late onset muscular dystrophy was naturally seen to be a disorder of adult life. On the other hand all cases of congenital MD had the disease present at birth. In fact, this group has been so named on account of the child being 


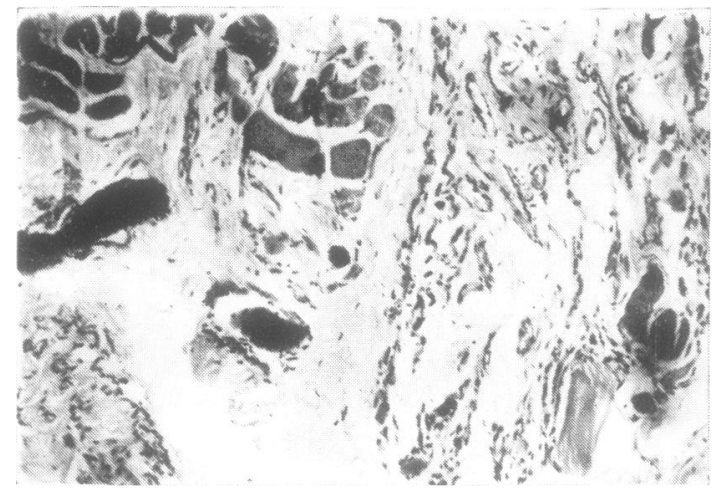

FIG. 1. (NP/526-b) Quadriceps muscle from case of limb-girdle dystrophy; groups of very small atrophied fibres along with better preserved fibres. $H$ and $E$, $\times 35$.

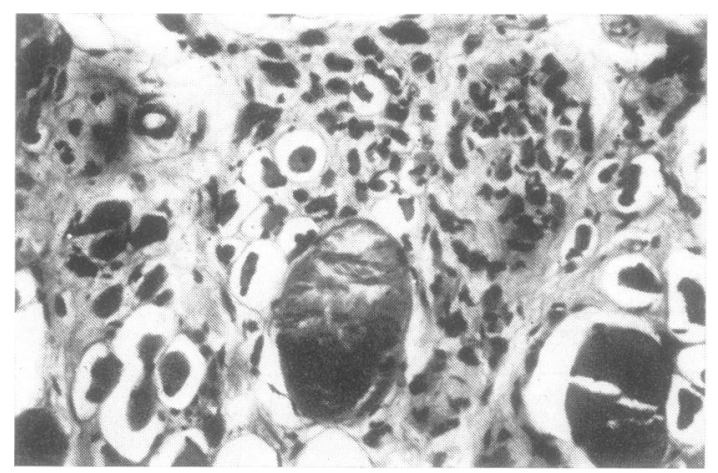

FIG. 2 (NP/F/909) Quadriceps muscle from case of facioscapulohumeral dystrophy; groups of angular atrophied fibres and intermediate sized fibres and stray hypertrophied fibres. $H$ and $E, \times 85$.

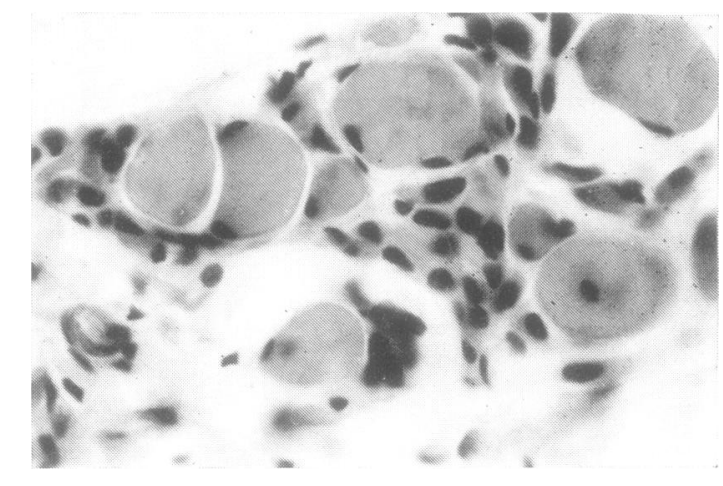

FIG. 3. (NP/E/320-a) Deltoid muscle from case of Duchenne muscular dystrophy; groups of small atrophied fibres with prominent nuclei amid large rounded fibres. $H$ and $E, \times 210$.

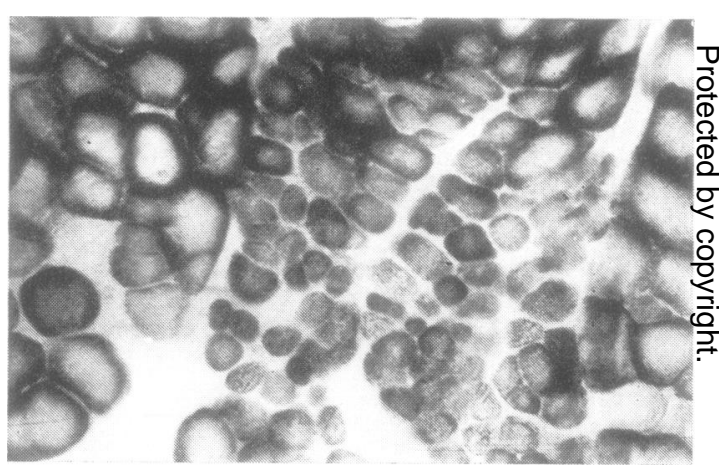

FIG. 4. $(N P / E / 260)$ Gastrocnemius muscle from case of limb-girdle dystrophy; frozen sections showing two groups of atrophied fibres with better preserved fascicles on either side. SDH, $\times 35$.

TABLE 3

PSEUDOMYOPATHIC CHANGES IN VARIOUS ANTERIOR HORN CELL DISORDERS

\begin{tabular}{|c|c|c|c|c|c|c|c|}
\hline & \multicolumn{3}{|c|}{ Spinal muscular atrophy } & \multirow{2}{*}{$\begin{array}{c}\text { Motor neurone } \\
\text { disease }\end{array}$} & \multirow[t]{2}{*}{ Poliomyelitis } & \multirow[t]{2}{*}{ Unclassifiable } & \multirow[t]{2}{*}{ Total } \\
\hline & Infantile & Juvenile & Adult & & & & \\
\hline No. of cases & 25 & 38 & 39 & 21 & 6 & 11 & 140 \\
\hline Pseudomyopathy & 4 & 15 & 13 & 7 & 1 & 3 & 43 \\
\hline Male & 13 & 26 & 29 & 19 & 6 & $6^{*}$ & 99 \\
\hline Female & 12 & 12 & $9 \dagger$ & 2 & - & $2^{*}$ & 37 \\
\hline
\end{tabular}

* Sex not known in three patients of this group.

$\dagger$ Not known in one. 
born with the clinical picture of muscular dystrophy.

While the old case records were not always complete, there was a history of illness similar to that in the proband in 16 families with DMD $(22 \%$ of 72$)$, all with Becker type MD, two girls with dystrophy resembling Duchenne type, two with limb-girdle, two with facioscapulohumeral, one with late onset, and two with congenital muscular dystrophy. Thus, 30 out of $179(16.7 \%)$ of patients with dystrophies gave a family history of dystrophy; there were probably many more. Similarly, the highest proportion of patients with a record of mental retardation was from the group of DMD, 11 of $72(15 \%)$ evidencing this feature. Only three patients with limb-girdle type and one with congenital dystrophy had mental retardation.

Clustering of 10 or more small muscle fibres, either angular or rounded, and the presence of such aggregates in different parts of the biopsy specimen were taken as evidence of group atrophy as defined in this paper. While most of the types of dystrophy listed in Table 1 revealed group atrophy, the largest proportion of such specimens was encountered in the limb-girdle, the facioscapulohumeral, and the congenital types of dystrophy. Eleven of the 72 specimens from DMD cases showed group atrophy. Considering all dystrophies together, 42 of the 179 cases $(23 \cdot 4 \%)$ showed group atrophy.

The groups of atrophic fibres, when present, were in addition to scattered small (atrophied) fibres detected constantly in all specimens of MD. Moreover, the group atrophy was encountered most frequently in the vicinity of large (hypertrophied) round fibres, but also mixing with the several intermediate sized fibres present in large or small numbers in all dystrophies. Central nucleation was not observed in atrophic fibres, either in groups or in singles, but was frequent in the large fibres. The atrophic fibre groups had no apparent relation to fibres undergoing necrosis, and they were clearly distinguishable from the basophilic regenerating fibres with large vesicular centrally placed nuclei. They were encountered irrespective of the presence of proliferated fibro-fatty tissue which was found to disorganize the fascicular pattern constantly and ruthlessly in dystrophic muscles. Group atrophy was not seen in specimens where the muscle tissue was almost totally destroyed and replaced by connective tissue. Rarely, an atrophic group was large enough to form the greater part of a fascicle. Figures 1 to 3 demonstrate these features in limb-girdle type, fascioscapulohumeral and Duchenne muscular dystrophy respectively, in paraffin sections. Frozen sections can also reveal group fibre atrophy in muscular dystrophy (Fig. 4).

Group atrophy amounting to fascicular atrophy was well seen in a case of limb-girdle dystrophy. In another patient, where the nerve to one of the bellies of the gastrocnemius muscle was cut at the first biopsy, clear group atrophy was not encountered. However, two months after denervation this part of the muscle showed fascicular atrophy but with the presence of excessive fat representing the dystrophic feature.

ANTERIOR HORN CELL DISORDER Denervation atrophy of muscle resulting from anterior horn cell disorder of one type or another constituted

\section{TABLE 4}

AGE AT EXAMINATION, DURATION, AND AGE OF ONSET IN VARIOUS ANTERIOR HORN CELL DISORDERS

\begin{tabular}{|c|c|c|c|c|c|}
\hline \multirow{2}{*}{$\begin{array}{l}\text { Anterior horn } \\
\text { cell disorder }\end{array}$} & \multicolumn{2}{|c|}{ Age $(y r)$} & \multicolumn{2}{|c|}{ Duration $(y r)$} & \multirow{2}{*}{$\begin{array}{c}\text { Average } \\
\text { age of } \\
\text { onset }(y r)\end{array}$} \\
\hline & Mean & Range & Average & Range & \\
\hline Infantile SMA & $3 \cdot 8$ & $0 \cdot 2-12$ & $1 \cdot 5$ & 0-9 & 0.4 \\
\hline Juvenile SMA & 13.4 & $2-29$ & $4 \cdot 5$ & $0.5-15$ & $8 \cdot 6$ \\
\hline Adult SMA & $30 \cdot 6$ & $20-60$ & $2 \cdot 5$ & $0 \cdot 5-12$ & $28 \cdot 5$ \\
\hline $\begin{array}{l}\text { Motor neurone } \\
\text { disease }\end{array}$ & $44 \cdot 3$ & $21-65$ & $1 \cdot 5$ & $0 \cdot 1-4$ & $41 \cdot 6$ \\
\hline Poliomyelitis & $11 \cdot 6$ & $1-27$ & $8 \cdot 0$ & $5-12$ & $6 \cdot 7$ \\
\hline
\end{tabular}

SMA $=$ Spinal muscular atrophy. $\mathbf{O}=$ From birth.

the second major item of investigation in the current study. The two main types of anterior horn cell disorder encountered were 102 cases of spinal muscular atrophy (SMA) of the infantile, juvenile, or adult sub-varieties; and 21 cases of motor neurone disease (MND) with evidence of both brain and cord involvement. In addition, there were six patients with a past history of acute anterior poliomyelitis. There were also 11 unclassifiable patients with clear denervation atrophy in their muscle biopsies but with no detailed case records available. 
TABLE 5

DIAMETERS OF MUSCLE FIBRES IN SELECTED GROUPS OF CASES

\begin{tabular}{|c|c|c|c|c|c|c|c|c|}
\hline \multirow[t]{2}{*}{ Type of dystrophy } & \multirow{2}{*}{$\begin{array}{l}\text { Subjects } \\
\text { (no.) }\end{array}$} & \multicolumn{3}{|c|}{ Atrophic groups } & \multicolumn{3}{|c|}{ Other fibres } & \multirow{2}{*}{$\begin{array}{c}\text { Mean age } \\
(y r)\end{array}$} \\
\hline & & $\begin{array}{c}\text { Specimens } \\
\text { (no.) }\end{array}$ & $\begin{array}{c}\text { Mean } \\
(\mu)\end{array}$ & $\begin{array}{c}\text { Range } \\
(\mu)\end{array}$ & $\begin{array}{c}\text { Specimens } \\
\text { (no.) }\end{array}$ & $\begin{array}{c}\text { Mean } \\
(\mu)\end{array}$ & $\begin{array}{c}\text { Range } \\
(\mu)\end{array}$ & \\
\hline Dushenne & 32 & 9 & $16 \cdot 3$ & $3-34$ & 32 & $46 \cdot 2$ & $10-130$ & $8 \cdot 9$ \\
\hline Limb-girdle & 10 & 6 & $21 \cdot 6$ & $10-37$ & 10 & $64 \cdot 0$ & $10-159$ & $19 \cdot 6$ \\
\hline Juvenile SMA & 19 & 16 & $17 \cdot 1$ & $6-43$ & 17 & $44 \cdot 2$ & $20-115$ & 13.0 \\
\hline Disuse atrophy & 14 & 4 & $20 \cdot 3$ & $10-27$ & 15 & $37 \cdot 1$ & $10-68$ & 43.0 \\
\hline Normal controls & 9 & - & - & - & 9 & $45 \cdot 3$ & $23-85$ & $36 \cdot 0$ \\
\hline
\end{tabular}

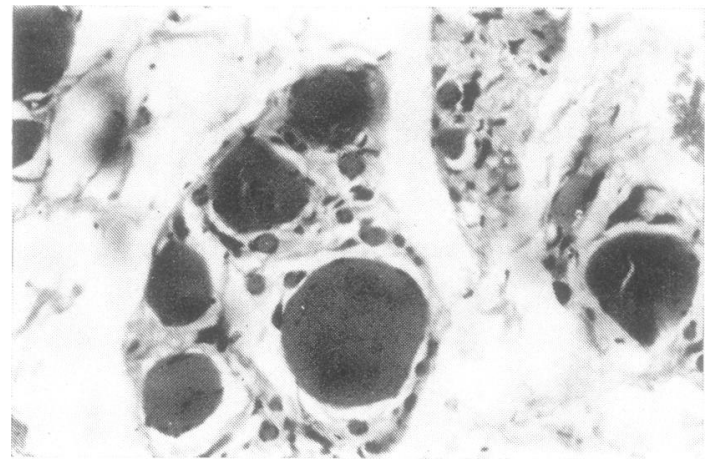

FIG. 5. (NP/C/556) Deltoid muscle from case of adult spinal muscular atrophy (SMA) showing rounded atrophied fibres contrasting with normal sized and hypertrophied fibres. $H$ and $E, \times 85$.

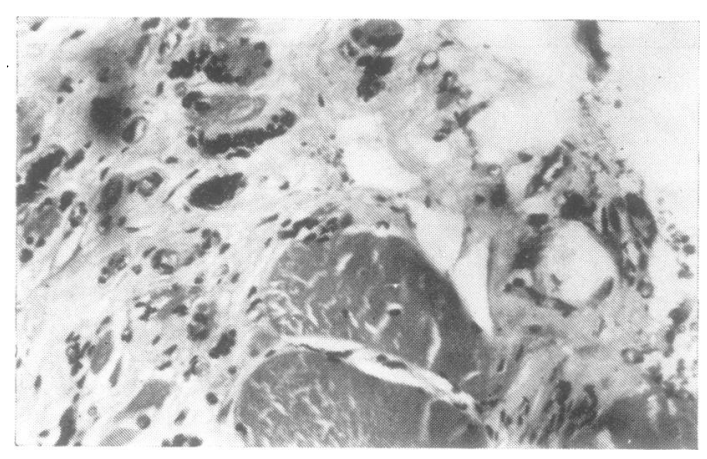

FIG. 6 (NP/A/196) Gastrocnemius muscle from case of adult SMA; knotted nuclei of chronically atrophied muscle fibres in fibrous matrix and hypertrophied fibres. $H$ and $E, \times 85$.

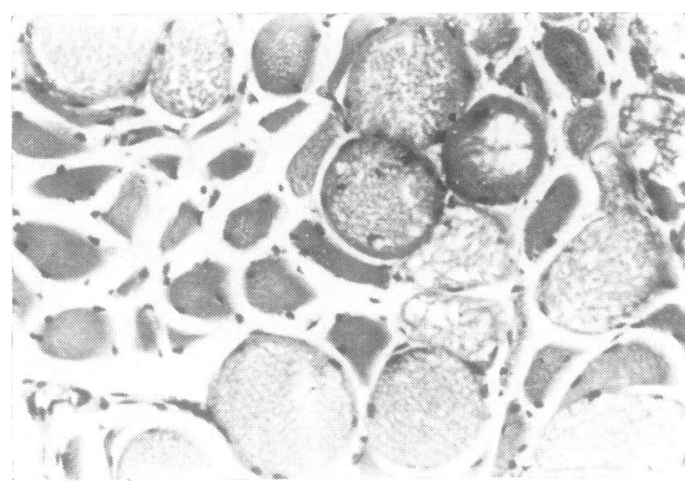

FIG. $7(N P / E / 731)$ Gastrocnemius muscle from cas $\overrightarrow{0}$ of juvenile SMA; another pseudomyopathic change int the form of rounded fibres undergoing vacuolar degeneration, along with atrophied fibres. $H$ and $E, \times 85$.

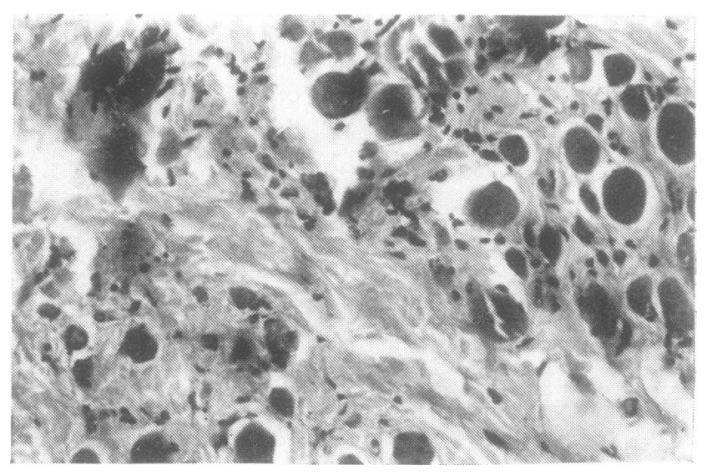

FIG. 8. (NP/E/685-b) Quadriceps muscle from case of juvenile SMA; extreme pseudomyopathic change including excessive proliferation of connective tissue. $H$ and $E, \times 85$. 
The incidence and classification of the various anterior horn cell disorders is given in Tables 3 and 4. The classification of spinal muscular atrophy into infantile, juvenile, and adult subvarieties was essentially according to age, the average ages at the time of presentation for the patients in these three groups being $3.8,13.4$, and 30.6 years respectively (Table 4 ). There was also a difference in the rate of progression of the disease in these three sub-groups, it being fastest in the infantile form. Many patients in this category were of the Werdnig-Hoffman type of anterior horn cell disease. In many of them the disease was present at birth so that the average age of onset was only 0.4 years, as in patients of group I and II of Byers and Banker (1961). However, there were several patients in this group with the age of onset clearly within the first $1 \frac{1}{2}$ year of life, but in whom the disease progressed slowly and hence the range of duration for this group was from 0-9 years. In contrast, the average age of onset of 8.6 years for our patients with juvenile SMA was comparable with the average age of 9 years for Kugelberg and Welander's (1956) syndrome. The progression of the disease was also slower in this group, with a duration extending to 15 years, and most of these patients had more proximal muscle involvement than distal. There was a recorded family history of illness similar to that in the sib

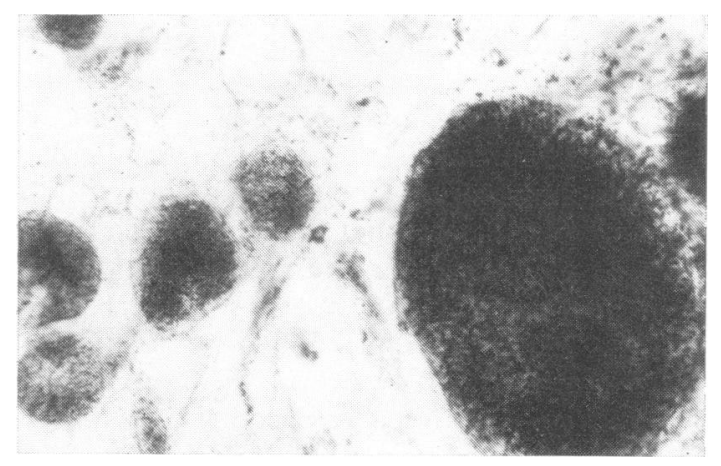

FIG. $9(N P / F / 990)$ Quadriceps muscle from case of Duchenne muscular dystrophy; frozen section showing almost exclusively type I fibres of varying size, enormously hypertrophied type I fibre measuring $180 \mu$. $S D H, \times 85$. in five families with infantile SMA, six with juvenile SMA, and one with adult SMA.

It was interesting to note a sizable proportion of adult patients with clear histological evidence of denervation, with no recorded clinical evidence of involvement of the upper motor neurone, and presenting with a picture essentially similar to that of juvenile SMA. These have been

TABLE 6

RATIO OF TYPE I TO TYPE II FIBRES IN SDH PREPARATIONS IN SELECTED GROUPS OF CASES

\begin{tabular}{lcccc}
\hline & \multicolumn{3}{c}{ Type of dystrophy } & $\begin{array}{l}\text { Normal } \\
\text { adults }\end{array}$ \\
\cline { 2 - 4 } & Duchenne & Becker type & Limb-girdle & \\
\hline Cases (no.) & 10 & 3 & 4 & 6 \\
Ratio I:II & $5 \cdot 5: 1$ & $4 \cdot 1: 1$ & $2 \cdot 8: 1$ & $1: 1 \cdot 3$ \\
\hline
\end{tabular}

classified as 'adult SMA'. The average ages of these patients was 30.6 years and the average age of onset was close to that (Table 4). The highest average age of 44.3 years was encountered in patients with motor neurone disease (MND), all of whom had evidenced both anterior horn cell and lateral column deficit, the picture being generally similar to that of amyotrophic lateral

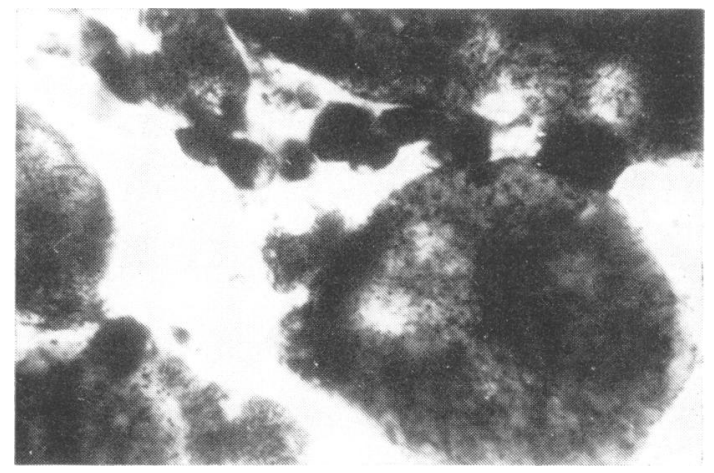

FIG. 10. (NP/E/487) Gastrocnemius muscle from case of juvenile SMA with myotonia; frozen section; predominating type I fibres, including both the atrophied and the hypertrophied. NADH2, $\times 210$. 
sclerosis (ALS). The average age of onset of the disease in these patients with MND was clearly higher ( 41.6 years) than that for the adult SMA group (Table 4). While the age of presentation for both these disorders ranged between the third and seventh decades, the duration was generally much shorter with MND, suggesting its severity. The age of patients with poliomyelitis varied from 1 year to 27 years and the duration of the disease varied from five years to 12 years (Table 4).

The term 'pseudomyopathic change' as used in this paper may be defined as that constellation of histological features which includes rounding and variation of fibre size, central nucleation of muscle fibres, and increase of connective tissue, with or without the additional presence of necrosis or regeneration of muscle fibres. Defined this way, cases of adult SMA and MND showed comparable proportions $(33 \%)$ of pseudomyopathic change; this change was more frequent in juvenile SMA and less frequent in infantile SMA (Table 3). In all specimens group atrophy was invariably present, whether in ill-defined groups mingling with better preserved or hypertrophied fibres, or as sharply defined groups or fascicles.

Figure 5 illustrates rounding, hypertrophy, and central nucleation of muscle fibres, in addition to atrophied fibres, all in a matrix of connective tissue. Even in the vicinity of severely atrophied fascicles with only nuclear clusters on remnants of fibres, hypertrophied fibres (Fig. 6) were often present. In the same specimen there was a small perivascular inflammatory focus. Vacuolar degeneration of fibres may be seen occasionally (Fig. 7) and even necrosis of a stray fibre in indubitable cases of spinal muscular atrophy. In a case of juvenile SMA who was examined by us on two successive occasions five years apart, along with variation of fibre size and occasional group atrophy, necrosis and regeneration of stray muscle fibres was observed. In one instance we were impressed by an excessive degree of fibrosis and an overtly 'myopathic' appearance of the muscle in parts of a specimen, the greater parts of which showed typical, and even fascicular denervation atrophy (Fig. 8). Muscles from one of our six patients with poliomyelitis manifested a pseudomyopathic change.
FIBRE DIAMETERS IN DYSTROPHIES AND ATROPHIES Fibre diameters were measured in a proportion of cases from some of the dystrophic and atrophic groups. In all cases the muscles included have been the large muscles of the leg, generally the quadriceps or the gastrocnemius and rarely, the tibialis anterior muscle. Table 5 gives the mean diameter as well as the range from the smallest to the largest fibre observed in a given sub-type and the number of specimens from which these data were obtained. These diameters have been obtained and expressed separately for the atrophic muscle fibre groups and the other fibres in the same specimen. The average ages mentioned in this Table have been calculated separately for the cases included in this Tablenamely, 32 patients with DMD, 10 with limbgirdle MD, 19 with juvenile SMA, 14 with disuse atrophy. These have been compared with diameters from nine normal muscles from nine subjects. The data on disuse atrophy does not form part of the present investigation but was collected in an earlier study of changes in the muscle in immobilized limbs of patients with fractures, etc. (Patel, Razzak, and Dastur, 1969) and the average for the mean fibre diameters have now been calculated for comparison with the similar data obtained from patients of the current study, particularly those with clear? denervation atrophy.

It is seen that a very wide range of fibre diameters obtains for the two types of muscular dystrophies included-namely, DMD and limbgirdle $\mathrm{MD}$, and almost as wide a range of diameters is noticed in denervated specimens from juvenile SMA. Moreover, the atrophied fibres from cases of DMD are almost as small as those from cases of juvenile SMA, the age difference between these groups being insignificant. It is interesting to note that the mean diameters (around $45 \mu$ ) of the fibres other than the atrophic groups are comparable not only with patients with DMD and juvenile SMA, but with those from normal subjects as well. This has happened despite a marked age difference between the two patient groups and the one control group. It is also seen that the mean fibre diameter $(c .20 \mu)$ for the atrophic groups in limb-girdle MD is very close to that for the atrophic groups in disuse atrophy. Though the average ages in these two groups differ markedly (19 and 43 years 
respectively), in fact they both represent striated muscle from adults.

RATIO OF FIBRE TYPES IN DYSTROPHIC MUSCLES Table 6 gives the limited data we have on the ratio of type I to type II fibres as observed in $\mathrm{SDH}$ preparations of a few selected groups of dystrophic patients. We have so far been impressed by a considerable preponderance of type I over type II fibres in DMD, where a ratio of 5.5:1 is observed. A similar but lesser preponderance has been noticed in the two other types of dystrophies mentioned in Table 6. This clearly contrasts with the ratio of type I:type II::1:1·3 in muscles from normal subjects, all except one being males.

Figure 9 illustrates the preponderance of type I fibres in one of our cases of DMD. In fact there were no clear type II fibres to be seen, the atrophied, the intermediate sized, and the hypertrophied fibres alike being strongly positive for the SDH reaction. The pertinence of this strong reaction in hypertrophied fibres will be discussed later. A very comparable picture was witnessed in some cases of spinal muscular atrophy (for example, Fig. 10) where, too, both the atrophied and the hypertrophied fibres were of type I.

\section{DISCUSSION}

Evidence has been presented from four different histological approaches to show a neurogenic factor in muscular dystrophy and to stress myopathological similarities between atrophies and dystrophies. These are: (1) the presence of group atrophy in $23 \%$ of biopsy specimens of muscular dystrophies; (2) the presence of myopathic features in about $30 \%$ of biopsy specimens of denervation atrophies; (3) the general presence of atrophied and hypertrophied fibres of comparable sizes, on measuring fibre diameters, in dystrophies and atrophies; and (4) a preponderance of type I fibres, suggesting depletion of type II fibres in dystrophic muscle.

Psychological, electrophysiological, and morphological evidence recently gathered by others, and pointing in the direction of a neurogenic factor in muscular dystrophy, has been presented in the introduction. The incidence of mental retardation among our patients with DMD might have been much higher than the $15 \%$ reported in this paper if these patients had been actually tested for IQ, etc. It is most pertinent to recall here that Duchenne's (1861) first case was mentally retarded and he suggested the name 'paraplégie hypertrophique de l'enfance de cause cérébrale'.

In muscle biopsies we selected group atrophy as the one reliable evidence of a denervation change. While this was encountered in only about a fourth of our dystrophic cases, it is well known that all specimens of muscle dystrophy show scattered atrophic fibres. This is brought out more clearly on estimating fibre diameters, especially when one notes the smallness of fibre size (the column on 'range' in Table 5) among fibres other than those of atrophic groups, for the two types of dystrophy. The majority of fibres in these groups of small fibres were considered atrophic, being of a size less than 2 SDs below the normal mean fibre diameter of $45 \cdot 3 \pm$ $9.8 \mu$ (Table 5) - that is, less than $25 \mu$. Greenfield, Shy, Alvord, and Berg (1957) encountered groups of fibres less than $40 \mu$ in size generally in muscle diseases.

In their meticulous study of muscle fibre diameters at different stages of DMD, Bell and Conen (1957) found that the mean fibre diameter was larger than in control subjects throughout early childhood. The increase in mean fibre diameter was said to progress from infancy till the age of 6 years and then to remain steady till the age of 9 years. In this context it is interesting to observe that the mean diameter of the fibres $(46.2 \mu)$ in the large leg muscles of our cases of DMD with a mean age of about 9 years was very close to the mean diameter of fibres $(45 \cdot 3 \mu)$ of comparable muscles of our normal adult controls with a mean age of 36 years (Table 5). It is also comparable with the mean fibre diameter $(44 \cdot 2 \mu)$ in muscles from patients with juvenile SMA of mean age of 12 years. The clearly larger mean fibre diameter $(64 \cdot 0 \mu)$ of our patients with limb-girdle MD, of mean age about 19 years, is probably the reflection of a number of truly hypertrophied fibres in this form of dystrophy. Thus, while the upper limit of the range of fibre diameters in DMD does indeed evidence hypertrophy (up to $130 \mu$ ) the upper limit of the range of fibre size in limb-girdle MD is even higher (up to $159 \mu$ ). Fibres of a size more than 2 SDs 
above $45 \mu$-that is, $65 \mu$ or more-may be considered hypertrophic. An appreciable degree of hypertrophy of fibres (up to $115 \mu$ in size) was clearly evident in muscles from juvenile SMA also, but was not noticed in adult patients with disuse atrophy due to immobilization (Patel et al., 1969), where the upper limit of fibre diameter was only $68 \mu$ and the mean fibre diameter was $37 \mu$. Hence at least the two forms of dystrophy analysed for fibre diameters seem to manifest a degree of atrophy and of hypertrophy comparable with the atrophy and the hypertrophy encountered in a typical disorder of the anterior horn cell-namely, juvenile SMA. In both these conditions, the hypertrophy is probably compensatory, a form of work hypertrophy involving the remaining unatrophied fibres in a muscle containing several atrophied fibres.

Clusters of small fibres in muscular dystrophy were observed by us earlier-for example, Fig. 5 of Dastur (1967) —but not reported as group atrophy. Such a change is probably the result of splitting of large 'dystrophic' fibres. Engel and Brooke (1966) mentioned the occasional presence of 'groups of small fibres' in dystrophic muscle but felt that they might be myopathic because they were rounded or showed internal derangement histochemically. Rounding appears to us to be a phenomenon of separation and lack of support to these from other muscle fibres, such as occurs more frequently in mid-stage dystrophies than in denervation atrophies. Compactly arranged atrophied fibres tend to remain angular in either of these conditions. In the late stages, both dystrophy and atrophy show disorganization with a tendency to rounding of the fibres, of whatever dimension they may be. Engel and Brooke conceded a "limited amount of "myopathic" change secondary to chronic denervation'. Drachman et al. (1967) have provided the most striking evidence derived from muscle biopsy of the 'myopathic' appearance of muscle in long-standing neurogenic atrophy.

Our own observation reported here of group atrophy representing a probable denervation change in about a fourth of the specimens of muscle dystrophy, and of pseudomyopathic changes in nearly a third of the specimens of denervation due to anterior horn cell disorders, is not considered fortuitous but a true reflection of the overlap between the histological reactions in these two different types of muscle disease. More specifically, it is considered evidence in favour of a neurogenic aetiological factor, possibly related to the spinal motor neurones, in human muscular dystrophies. The evidence is further reinforced by the overlap of fibre diameters for both atrophied and hypertrophied fibres in the dystrophies and the denervation atrophies.

Finally, 'type atrophy' of any type of fibre is generally accepted to indicate a denervation process particularly affecting anterior horn cells (Engel, 1970). Our small observation of a preponderance of type I fibres in SDH preparations of most of the dystrophies examined suggests a selective depletion of type II fibres and again points to a neurogenic factor. It was interesting to note a similar preponderance of type I fibres (more than $60 \%$ of total) in most of the dystrophic cases of Brooke and Engel (1969) where the proportions of the two main types of fibres have $\omega$ been calculated in individual patients. Moreovero $\dot{\omega}$ it may be recalled that in our material the smali (atrophied), the intermediate sized, and the large (hypertrophied) fibres were seen to belong to type I. The artefactual creation of type I fibres in SDH preparations by a crowding of mit $\&$ chondria in small fibres, is well recognize (Engel, 1970). Preponderance of type I fibres ws also noticed by us in the biopsies of the more affected muscles from our cases of arthrogryposis multiplex congenita (AMC), pointing to either denervation at the anterior horn cell level or lack of development of the motor neurone or of the $\frac{\mathrm{Q}}{\mathbb{Q}}$ muscle itself. Most of the large fibres encountered there were also of type I (Dastur, Razzak, and Bharucha, 1972). Moreover, all these fibres from our cases of AMC, were embedded in a dense fibrous and fatty matrix comparable with that observed in typical muscular dystrophy. The latter feature perhaps points to the non-specificity of connective tissue overgrowth in dystro- 3 . phies.

On the basis of the evidence presented above, it is considered legitimate to question the concept 윽 of muscular dystrophies being 'primary' muscle $>$ disorders. This is not to deny some striking differences between denervation atrophies and N dystrophies as regards the level of serum CPK and the electromyographic changes. The N raised concentration of serum CPK is believed 
to be an effect of damage to the membrane of the cell (Adams, Denny-Brown, and Pearson, 1962; Pennington, 1969), and is observed even more severely in chronic polymyositis than in muscular dystrophy. It is not elevated, except mildly and occasionally, in the spinal muscular atrophies, where a break in the fibre membrane was believed not to occur. However, recent electronmicroscopic observations have revealed some identity of ultrastructural change in the muscle fibre in dystrophy and in denervation, in the form of disruption of internal architecture notably in the region of the Z-bands (Milhorat, Shafiq, and Goldstone, 1966; Shafiq, Milhorat, and Golycki,'1967; Hudgson and Pearce, 1969). The rate and manner of breakdown of muscle fibres appears more responsible for the release of $\mathrm{CPK}$, than any alleged difference in pathogenesis -such as 'myopathic' or 'neuropathic'. A process such as microinfarction would be more likely to release this enzyme, and the recent suggestion of Hathaway, Engel, and Zellweger (1970), that embolization of intramuscular vessels with resultant infarction closely simulates spontaneous muscular dystrophy, is most thought-provoking. $\dot{A}$ propos of this, it may be recalled that it is the large hypertrophied fibre which exhibits successively the typical 'dystrophic' changes of rounding and homogenization, central nucleation, and, terminally, either splitting or necrosis. This chain of reactions could well result from ischaemia of such muscle fibres.

The argument about dissimilarity of electromyographic features in dystrophies and denervation atrophies has been met to a considerable extent by the recent careful electrical analysis of motor units by McComas et al. (1971). They have demonstrated a loss of motor units in three different types of muscular dystrophy and, from the size of the surviving motor units, suggested that the condition resulted from disordered function of motoneurones, or 'sick' motoneurones. In the presence of such sick motoneurones, they aver, histological examination of the muscle may not reveal grouping of the fibres. Thus, in a chronic partially denervated muscle, the 'myopathic' quality will be greater the more sick motoneurones there are among the survivors. The very recent finding of Caspary, Currie, and Field (1971) of sensitization of lymphocytes from patients with muscular dystrophy by antigens from both muscle and nerve, is compatible with a neurogenic factor in the pathogenesis of this disease.

We are grateful to the several physicians and surgeons who have referred to us biopsy material over the years, notably to Dr. N. H. Wadia, honorary neurologist, J. J. Hospitals, and Dr. E. P. Bharucha, honorary neurologist, Children's Orthopaedic and K.E.M. Hospitals. It is a pleasure to acknowledge the assistance received from the technicians of this Unit, Mr. V. Talwadkar and Mr. P. B. Nath, and to Mr. N. Solanki. Grateful acknowledgement is due to the Muscular Dystrophy Group of Great Britain for a research grant during the period 1967-70, and to the Muscular Dystrophy Association of America for a research grant from January 1972 for supporting Miss Z. A. Razzak.

\section{REFERENCES}

Adams, R. D., Denny-Brown, D., and Pearson, C. M. (1962). Diseases of Muscle. A Study in Pathology. 2nd edn. Harper: New York

Bell, C. D., and Conen, P. E. (1967). Change in fiber size in Duchenne muscular dystrophy. Neurology (Minneapolis), 17, 902-913.

Brooke, M. H., and Engel, W. K. (1969). The histographic analysis of human muscle biopsies with regard to fiber types. Neurology (Minneapolis), 19, 221-233.

Byers, R. K., and Banker, B. Q. (1961). Infantile muscular atrophy. Archives of Neurology, 5, 140-164.

Caspary, E. A., Currie, S., and Field, E. J. (1971). Sensitized lymphocytes in muscular dystrophy. Journal of Neurology, Neurosurgery, and Psychiatry, 34, 353-356.

Cohen, H. J., Molnar, G. E., and Taft, L. T. (1968). The genetic relationship of progressive muscular dystrophy (Duchenne type) and mental retardation. Developmental Medicine and Child Neurology, 10, 754-765.

Dastur, D. K. (1967). Muscle disorders. A study in histological reactions. Indian Journal of Pathology and Bacteriology, 10, 184-192.

Dastur, D. K., Razzak, Z. A., and Bharucha, E. P. (1972). Arthrogryposis multiplex congenita. Part 2. Muscle pathology and pathogenesis. Journal of Neurology, Neurosurgery, and Psychiatry, 35, 435-450.

Drachman, D. B., Murphy, S. R., Nigam, M. P., and Hills, J. R. (1967). "Myopathic" changes in chronically denervated muscle. Archives of Neurology, 16, 12-24.

Dubowitz, V. (1969). Chemical and structural changes in muscle: the importance of the nervous system. In Some Inherited Disorders of Brain and Muscle, pp. 32-43. Edited by J. D. Allan and D. N. Raine. Proceedings of the Fifth Symposium of the Society for the Study of Inborn Errors of Metabolism. Livingstone: Edinburgh.

Duchenne, G. B. A. (1861). De l'Électrisation Localisée et son Application à la Pathologie et à la Thérapeutique. 2nd end. Baillière: Paris.

Engel, W. K. (1970). Selective and nonselective susceptibility of muscle fibre types. A new approach to human neuromuscular diseases. Archives of Neurology, 22, 97-117.

Engel, W. K., and Brooke, M. H. (1966) Muscle biopsy as a clinical diagnostic aid. In Neurological Diagnostic Tech- 
niques, pp. 90-146. Edited by W. S. Fields. Thomas: Springfield, Ill.

George, J. C., and Talasera, C. L. (1961). Histological observations on the succinic dehydrogenase and cytochrome oxidase activity in pigeon breast-muscle. Quarterly Journal of Microscopical Science, 102, 131-141.

Greenfield, J. G., Shy, G. M., Alvord, E. C., Jr., and Berg, L. (1957). An Atlas of Muscle Pathology in Neuromuscular Diseases. Livingstone: Edinburgh.

Hathaway, P. W., Engel, W. K., and Zellweger, H. (1970). Experimental myopathy after microarterial embolization. Archives of Neurology, 22, 365-378.

Hudgson, P., and Pearce, G. W. (1969). Ultramicroscopic studies of diseased muscle. In Disorders of Voluntary Muscle, pp. 277-317. Edited by J. N. Walton. 2nd edn. Churchill: London.

Hughes, B. P. (1962) A method for the estimation of serum creatine kinase and its use in comparing creative kinase and aldolase activity in normal and pathological sera. Clinica Chimica Acta, 7, 597-603.

Kondo, K. (1969). Contribution to the pseudo-dystrophic nature of muscular atrophy in Wohlfart-KugelbergWelander's disease. Acta Neuropathologica, 13, 29-42.

Kugelberg, E., and Welander, L. (1956). Heredofamilial juvenile muscular atrophy simulating muscular dystrophy, Archives of Neurology and Psychiatry, 75, 500-509.

McComas, A. J., and Mrożek, K. (1967). Denervated muscle fibres in hereditary mouse dystrophy. Journal of Neurology, Neurosurgery, and Psychiatry, 30, 526-530.

McComas, A. J., Sica, R. E. P., and Currie, S. (1970). Muscular dystrophy: evidence for a neural factor. Nature, 226, 1263-1264.
McComas, A. J., Sica, R. E. P., Currie, S., and Campbell, M. J. (1971). 'Sick' motoneurones. A unifying concept of muscle disease. Lancet, 1, 321-325.

Milhorat, A. T., Shafiq, S. A., and Goldstone, L. (1966). Changes in muscle structure in dystrophic patients, carriers and normal siblings seen by electron microscopy; correlation with levels of serum creatinephosphokinase (CPK). Annals of the New York Academy of Sciences, 138, 246292.

Patel, A. N., Razzak, Z. A., and Dastur, D. K. (1969). Disuse atrophy of human skeletal muscles. Archives of Neurology20, 413-421.

Pennington, R. J. T. (1969). Biochemical aspects of muscle $\Rightarrow$ disease. In Disorders of Voluntary Muscle, pp. 385-410. Edited by J. N. Walton. 2nd edn. Churchill: London.

Rosman, N. P., and Kakulas, B. A. (1966). Mental deficiency associated with muscular dystrophy. A neuropathologica study. Brain, 89, 769-788.

Shafiq, S. A., Milhorat, A. T., and Gorycki, M. A. (1967) Fine structure of human muscle in neurogenic atrophy. Neurology (Minneapolis), 17, 934-948.

Takeuchi, T. (1958). Histochemical demonstration of branching enzyme (amylo-1, 4 $\rightarrow$ 1, 6-transglucosidase) in animal tissues. Journal of Histochemistry and Cytochemistry, 6. 208-216.

Zellweger, H., and Hanson, J. W. (1967). Psychometric studies in muscular dystrophy type IIIa (Duchenne) Developmental Medicine and Child Neurology, 9, 576-581.

Zellweger, H., and Niedermeyer, E. (1965). Central nervous system manifestations in childhood muscular dystrophy $\omega$ (CMD). I. Psychometric and electroencephalographe $\omega$ findings. Annales Paediatrici (Basel), 205, 25-42. 